\title{
RESPONSE SURFACE METHODOLOGY TO MODEL THE ELECTROSTATIC PRECIPITATION OF NANOPARTICLES AT LOW AIR VELOCITIES
}

\author{
A. E. de OLIVEIRA ${ }^{1}$ and V. G. GUERRA ${ }^{1, *}$
}

${ }^{1}$ Federal University of São Carlos, Graduate Program of Chemical Engineering, São Carlos, SP, Brazil

${ }^{*}$ Corresponding author. Federal University of São Carlos, Department of Chemical Engineering, São Carlos, SP, Brazil, Phone: +55 16 $3351-8264$

e-mail address: vadila@ufscar.br (V.G. Guerra).

\begin{tabular}{l} 
A R T I C L E I N F O \\
\hline Article history: \\
Received 2020-07-28 \\
Accepted 2020-10-20 \\
Available online 2020-10-20 \\
p a l a vra $s$ - ch a ve \\
Precipitação eletrostática \\
Nanopartículas \\
Controle Ambiental \\
Metodologia de superfície de \\
resposta \\
\\
$k e y w$ o $r d s$ \\
Electrostatic precipitation \\
Nanoparticles \\
Environmental control \\
Response Surface Methodology \\
\end{tabular}

\begin{abstract}
A B S T R A C T
Low air velocities are not fully explored yet in the field of electrostatic precipitation due to the size limitations of the industrial devices, but they had provided high collection efficiencies for nanoparticles in studies in laboratory scale. In order to contribute to the science of electrostatic precipitation, a full $3^{2}$ factorial design of experiments was performed to evaluate the effect of operating conditions (applied voltages from -8.0 to $-8.2 \mathrm{kV}$ and air velocities from 1.67 to $19.9 \mathrm{~cm} \mathrm{~s}^{-1}$ ) on the overall mass efficiency of electrostatic precipitation of $\mathrm{KCl}$ nanoparticles (5.94-224.7 nm). Response Surface Methodology was used to assess the range of operating conditions that provide the highest efficiencies. The highest percentual efficiency $(99.870 \pm 0.008)$ was obtained for $-8.2 \mathrm{kV}$ and $6.67 \mathrm{~cm} \mathrm{~s}^{-1}$. A polynomial model fitted well the experimental data $\left(R^{2}=0.99217\right)$.
\end{abstract}




\section{INTRODUCTION}

Different numerical, theoretical, and fitting models have been purposed to predict the collection efficiency and the gas flow patterns of dry and wet electrostatic precipitators (ESPs). Guo et al. (2017) used Computational Fluid Dynamics (CFD) to model the efficiency of a wire-plate electrostatic precipitator capturing dry and wet ash particles $(0.02-2.5 \mu \mathrm{m})$ from flue gas at $1 \mathrm{~m} \mathrm{~s}^{-1}$ and considering the presence of $\mathrm{SO}_{3}$. The gas flow was modelled using the k- $\omega$ SST turbulence model while a random walk approach was used to simulate particle dispersion. It was possible to evaluate the effect of the temperature $(90,120$, and $\left.150{ }^{\circ} \mathrm{C}\right)$, the particle concentration $\left(1\right.$ and $\left.10 \mathrm{~g} \mathrm{Nm}^{-3}\right)$, and the dielectric constant for dry and wet particulate $(3.9,6.6$, and 80$)$ on the collection efficiency. Lin and Tsai (2010) purposed a numerical model to predict the collection efficiency in laminar flow of dry and wet wire-plate ESPs capturing nanoparticles with sizes from 6 to $100 \mathrm{~nm}$ at $100 \mathrm{~L} \mathrm{~min}^{-1}$ and with sizes from 10 to $50 \mathrm{~nm}$ at $5 \mathrm{~L} \mathrm{~min}^{-1}$, respectively. The model was validated with the experimental data, providing deviations smaller than $20 \%$ for the dry ESP simulation compared to the data from the literature. Numerical studies also include the work of Kherbouche et al. (2017) modelling the efficiency of an asymmetrical wire-plate ESP collecting cement particles $(0.8-5$ $\mu \mathrm{m})$ at $0.1 \mathrm{~m} \mathrm{~s}^{-1}$ of air and the study of Zhang et al. (2011) modelling the performance of a wire-plate ESP under magnetic field collecting ash particles $(\sim 3-50 \mu \mathrm{m})$ at air velocities from 0.5 to $1.0 \mathrm{~m} \mathrm{~s}^{-1}$. Other studies have extended the classical Deutsch's model (2003) to develop theoretical or semiempirical models based on the mass balance of the particle passing through the ESP (Zhibin and Guoquan, 1994; Bai et al., 1995; Nóbrega et al., 2004; Lin et al., 2012; Chen et al., 2014).

Therefore, the aim of the present work is to contribute to the field of electrostatic precipitation by fitting an efficiency model to experimental data provided by a wire-plate ESP removing $\mathrm{KCl}$ nanoparticles $(5.94-224.7 \mathrm{~nm})$ in a range of low air velocities, which are not fully explored yet due to size limitations of the industrial devices, but that provided high collection efficiencies for nanoparticles in studies in laboratory scale (Oliveira and Guerra, 2018, 2019 a, b). Since ESPs are already used in the retention of ultrafine particles of valuable materials in laboratory-scale syntheses (Nanda et al., 2011; Harra et al., 2012; Lähde et al., 2014), the optimization of the operating conditions to collect nanometric particulate could be useful to guarantee the efficiency of these systems and processes in order to be further performed in large scale.

ANOVA and $\mathrm{R}^{2}$ were used to assess respectively the statistical validation of the effects of the operating conditions (electric field and air velocity) on the collection efficiency and the polynomial fitting equation on the experimental results. Response Surface Methodology (RSM) was used to assess the ranges of the operating conditions that provide optimal efficiencies. The experiments were performed following a full $3^{2}$ design of experiments, which were performed in triplicate.

\section{MATERIALS AND METHODS}

The experimental system (Figure 1) consisted of a dry single-stage wire-plate electrostatic precipitator. The collection plates were made of copper and the discharge electrodes (arranged in the longitudinal axis of the ESP) were composed of stainless steel. The system also includes a gas compressor, prefilters (Model 3047B, TSI), an atomizer aerosol generator (Model 3076, TSI), a diffusion-dryer (Model 3062, TSI), Kr-85 and Am-241 radioactive sources used as aerosol neutralizers, a power supply (for negative corona), a flowmeter, and an electrical mobility particle analysis system (SMPS) consisting of an electrostatic classifier (Model 3080, TSI) and a particle counter (Model 3776, TSI).

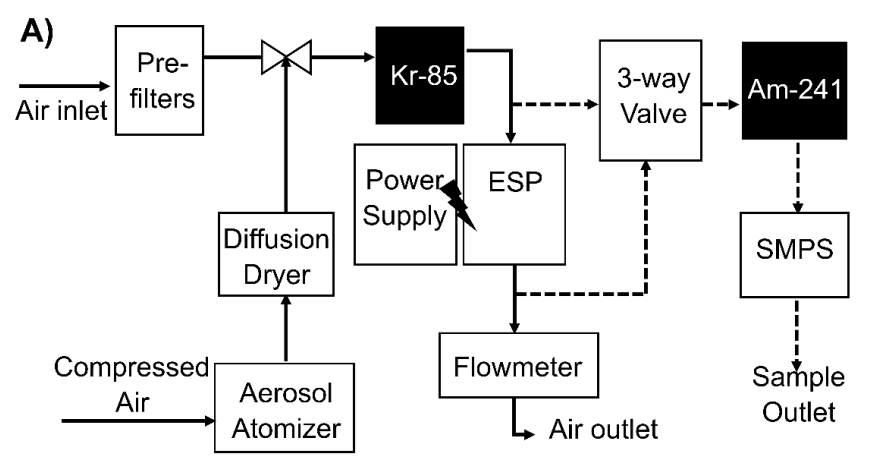

B)

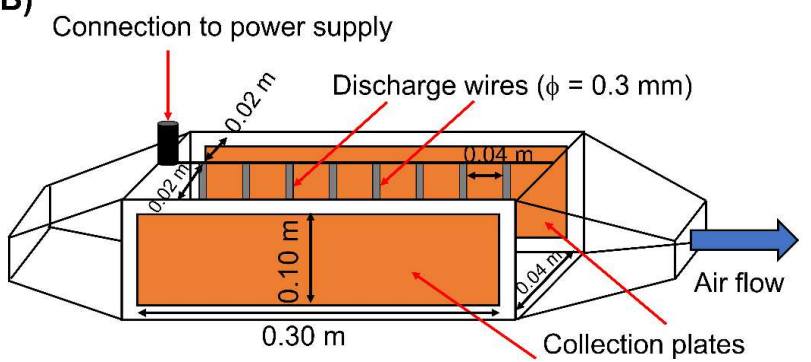

Figure 1 - Schematics of the experimental system (a) and the ESP (b)

Air $\left(25^{\circ} \mathrm{C}\right.$ and 0.92 atm; viscosity: $1.79 \times 10^{-5} \mathrm{~Pa} \mathrm{~s}$; density: $1.08 \mathrm{~kg} \mathrm{~m}^{-3}$ (Riehle, 1997), humidity below $20 \%$ R.H.) was fed by the compressor and passed through the pre-filters to remove impurities with the flow rate controlled by valves. The atomizer aerosol generator injected compressed air through a nozzle where it atomized a $\mathrm{KCl}$ solution (Bulk properties: density: 1,988 $\mathrm{kg} \mathrm{m}^{-3}$; dielectric constant: 4.81 (Robinson and Hollis-Hallet, 1966; Dean, 1999)), in order to create a polydisperse aerosol of which coarser particles were retained by an impactor within the device, resulting in the emission of particles smaller than $1 \mu \mathrm{m}$, at a controlled volumetric gas flow rate of $100 \mathrm{NL} \mathrm{h}^{-1}$. The aerosol passed through the diffusiondryer and was then mixed with the main air stream. The power supply was connected to the ESP to produce the electric current used to ionize the air molecules. $\mathrm{Kr}-85$ and Am-241 radioactive sources were installed respectively after the diffusion-dryer and the ESP, in order to neutralize the charges of the particles hence avoiding disturbances in the SMPS analysis. Aerosol samples were continuously withdrawn from the inlet or the outlet of the ESP at $1.5 \mathrm{~L} \mathrm{~min}^{-1}$ using a three-way valve and entered the SMPS after passing through the Am-241 neutralizer. The particles were separated according to their electrical mobility in the device. The monodispersed aerosol produced in the 
electrostatic classifier was passed to the particle counter for the measurement of the particle concentration during $315 \mathrm{~s}$ for each replicate. The experimental overall collection efficiency $\left(E_{f f}\right)$ was calculated from the relation between the particle mass concentrations in the inlet $\left(c_{i}\left[\mu \mathrm{g} \mathrm{m}^{-3}\right]\right)$ and the outlet $\left(c_{o}\left[\mu \mathrm{g} \mathrm{m}^{-}\right.\right.$ $\left.\left.{ }^{3}\right]\right)$ of the ESP as Equation 1:

$$
E_{f f}=100 \times\left(c_{i}-c_{o}\right) / c_{i}
$$

Since $c_{i}$ and $c_{o}$ were measured in triplicate, it was possible to calculate the mean values of efficiency and the respective deviations for each test.

In this study, the applied voltage (Volt) and the face air velocity $(V)$, this latter given as the ratio between the volumetric flow rate of the air and the cross-sectional area of the ESP $(0.004$ $\mathrm{m}^{2}$ ), were evaluated as the independent variables and Eff was the response. $\mathrm{KCl}$ solutions with different concentrations were prepared according for each $V$ evaluated in order to maintain a constant aerosol concentration, following a methodology presented in the literature (Oliveira and Guerra, 2018, 2019 a). Three values of Volt and $V$ were used for the fitting model (Table 1) and an additional set of experimental conditions using the three levels of Volt at the air velocity of $3.33 \mathrm{~cm} \mathrm{~s}^{-1}(\mathrm{KCl}$ concentration of $1.0 \mathrm{~g} \mathrm{~L}^{-1}$ ) were performed to validate the polynomial equation.

Table 1 - Nomenclature of the tests.

\begin{tabular}{|c|c|c|c|}
\hline $\begin{array}{c}\text { Coded } \\
\text { values }\end{array}$ & $\begin{array}{c}\text { Volt } / \\
\mathrm{kV}\end{array}$ & $\begin{array}{c}\mathrm{V} \\
\mathrm{cm} \mathrm{s}^{-1}\end{array}$ & $\mathrm{KCl}$ concentration $/ \mathrm{g} \mathrm{L}^{-1}$ \\
\hline-1 & -8.2 & 1.67 & 0.5 \\
\hline 0 & -8.1 & 6.67 & 2.0 \\
\hline+1 & -8.0 & 19.9 & 6.0 \\
\hline
\end{tabular}

The electrical characterization of the system according to the air velocities evaluated is presented in Figure 2.

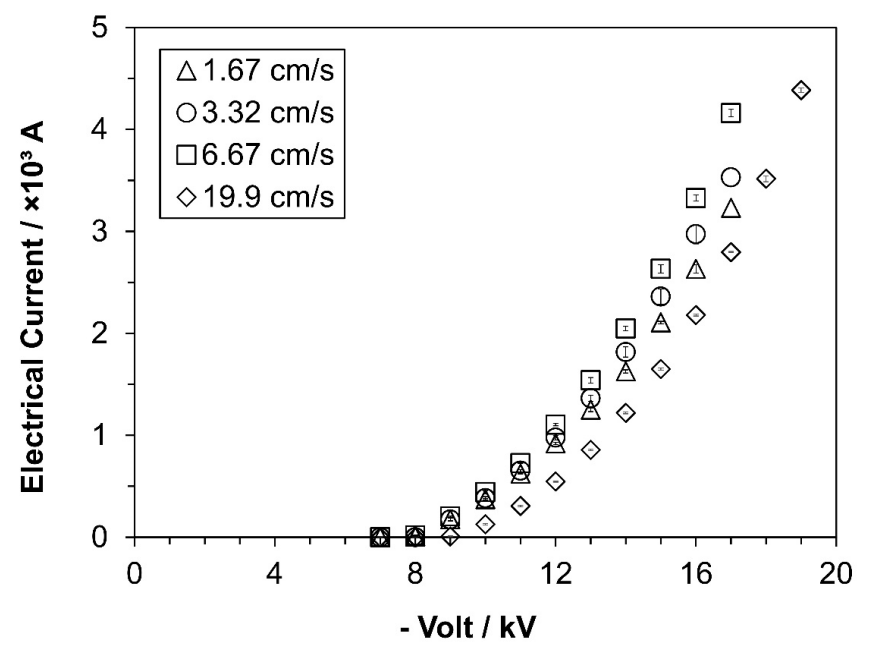

Figure 2 - Current-voltage curves for the air velocities evaluated

Response surface methodology was used to evaluate the operating conditions to collect the nanoparticles by electrostatic precipitation, performing the full $3^{2}$ design of experiments (Table 1) and proposing a second-order fit for the response (Montgomery and Runger, 2014). Software Statistica (2011) was used to perform the regression calculations from the experimental data, to plot the statistical graphs, and to perform the ANOVA and $\mathrm{R}^{2}$ analyses to validate the tests statistically and the curve fitting, respectively. A 95\% confidence interval was considered for the analyses. The fitting model applied in the experimental data considered the two-way interactions between the linear $(L)$ and the quadratic $(Q)$ effects of the independent variables, since the collection efficiency of electrostatic precipitation depends inversely on the gas velocity and directly on the squared electric field, as can be expressed on the dimensionless number called Deutsch number of the Deutsch model: this parameter depends on the migration velocity of the particle, the length of the collection plate, and the wire-plate spacing, being the migration velocity dependent implicitly on the squared electric field (given as the ratio between Volt and the plate spacing) (Riehle, 1997; Oliveira and Guerra, 2019 a).

\section{RESULTS AND DISCUSSION}

Table 2 presents the experimental results of the tests while Figure 3 presents the mean efficiencies in relation to the applied main effects with the respective standard deviations.

Table 2 - Experimental results.

\begin{tabular}{|c|c|c|}
\hline Volt / kV & $\mathrm{V} / \mathrm{cm} \mathrm{s}^{-1}$ & $\mathrm{E}_{\mathrm{ff}} / \%$ \\
\hline-1 & -1 & 99.80 \\
\hline-1 & 0 & 99.88 \\
\hline-1 & +1 & 27.02 \\
\hline 0 & -1 & 91.32 \\
\hline 0 & 0 & 99.82 \\
\hline 0 & +1 & 14.23 \\
\hline+1 & -1 & 36.63 \\
\hline+1 & 0 & 99.01 \\
\hline+1 & +1 & 20.85 \\
\hline-1 & -1 & 99.54 \\
\hline-1 & 0 & 99.86 \\
\hline-1 & +1 & 24.24 \\
\hline 0 & -1 & 98.60 \\
\hline 0 & 0 & 99.69 \\
\hline 0 & +1 & 12.41 \\
\hline+1 & -1 & 40.18 \\
\hline+1 & 0 & 94.51 \\
\hline+1 & +1 & 20.34 \\
\hline-1 & -1 & 99.48 \\
\hline-1 & 0 & 99.87 \\
\hline-1 & +1 & 19.07 \\
\hline 0 & -1 & 98.16 \\
\hline 0 & 0 & 99.72 \\
\hline 0 & +1 & 25.74 \\
\hline+1 & -1 & 37.43 \\
\hline+1 & 0 & 98.39 \\
\hline+1 & +1 & 7.66 \\
\hline
\end{tabular}

It is verified that the increase of the air velocity from 1.67 to $6.67 \mathrm{~cm} \mathrm{~s}^{-1}$ enhanced the efficiency while the further increase of $V$ decreased the response for the size range of voltages evaluated. This first increase of efficiency was reported in the literature and was mainly related to the enhancement of the Brownian motion for the nanoparticles in a velocity range in which diffusion is prominent between those particles (Oliveira and Guerra, 2019 a). Further increase of the air velocity corresponded to the decrease of the residence time to charge and 
collect the particles (Zhuang et al., 2000; Huang and Chen, 2002; Morawska et al., 2002; Kim et al., 2010). In the other hand, the increase of the applied voltage increased the efficiency for the range of $V$ evaluated, which is associated to the increase of the electric field that produces the electrical charges by the corona effect and also to the increase of the field strength needed to attract the charged particles to the collection plates (Parker, 2003; Oliveira and Guerra, 2018, 2019 a). The subsequent increase of the electrical current caused by the increase of the charges inside the ESP provides the formation of von Kármán vortexes and increases the turbulent mixing in the device, enhancing the efficiency (Fujishima et al., 2006; Podliński et al., 2006; Oliveira and Guerra, 2019 b).

Experimental data was analyzed by ANOVA, according to Table 3 .

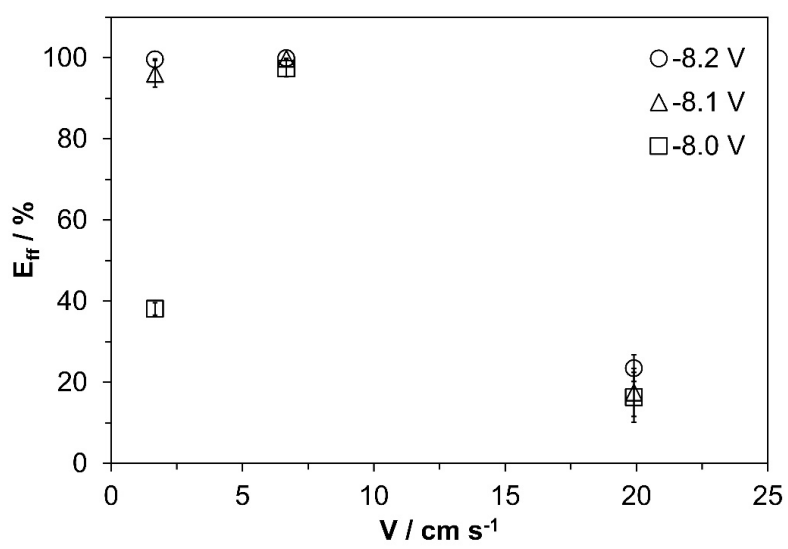

Figure 3 - Overall mass efficiencies according to $V$ at different Volt

Table 3 - ANOVA for overall mass efficiency.

\begin{tabular}{|c|c|c|c|c|c|}
\hline Factor & Sum of Squares & Degrees of Freedom & Mean Square & F-test & P-value \\
\hline Volt $(\mathrm{kV})-\mathrm{L}$ & $1,682.3$ & 1 & $1,682.3$ & 100.6 & $8.5 \times 10^{-9}$ \\
\hline Volt $(\mathrm{kV})-\mathrm{Q}$ & 239.1 & 1 & 239.1 & 14.3 & $1.4 \times 10^{-3}$ \\
\hline V $(\mathrm{cm} / \mathrm{s})-\mathrm{L}$ & $15,580.8$ & 1 & $15,580.8$ & 931.9 & $5.9 \times 10^{-17}$ \\
\hline V $(\mathrm{cm} / \mathrm{s})-$ Q & $7,777.6$ & 1 & $7,777.6$ & 465.2 & $2.6 \times 10^{-14}$ \\
\hline VoltL by VL & $2,216.8$ & 1 & $2,216.8$ & 132.6 & $9.8 \times 10^{-10}$ \\
\hline VoltL by VQ & $1,816.9$ & 1 & $1,816.9$ & 108.7 & $4.7 \times 10^{-9}$ \\
\hline VoltQ by VL & 875.4 & 1 & 875.4 & 52.4 & $9.9 \times 10^{-7}$ \\
\hline VoltQ by VQ & 400.6 & 1 & 400.6 & 24.0 & $1.2 \times 10^{-4}$ \\
\hline Error & 300.9 & 18 & 16.7 & & \\
\hline Total SS & $38,433.7$ & 26 & & & \\
\hline Volt L+Q & $1,921.4$ & 2 & 960.7 & 57.5 & $1.5 \times 10^{-8}$ \\
\hline V L+Q & $30,875.6$ & 2 & $15,437.8$ & 923.4 & $7.3 \times 10^{-19}$ \\
\hline Volt*V & $4,270.2$ & 4 & $1,067.5$ & 63.9 & $2.2 \times 10^{-10}$ \\
\hline
\end{tabular}

The statistical evaluation of the effects on the response can be visualized in the pareto chart of Figure 4 as well.

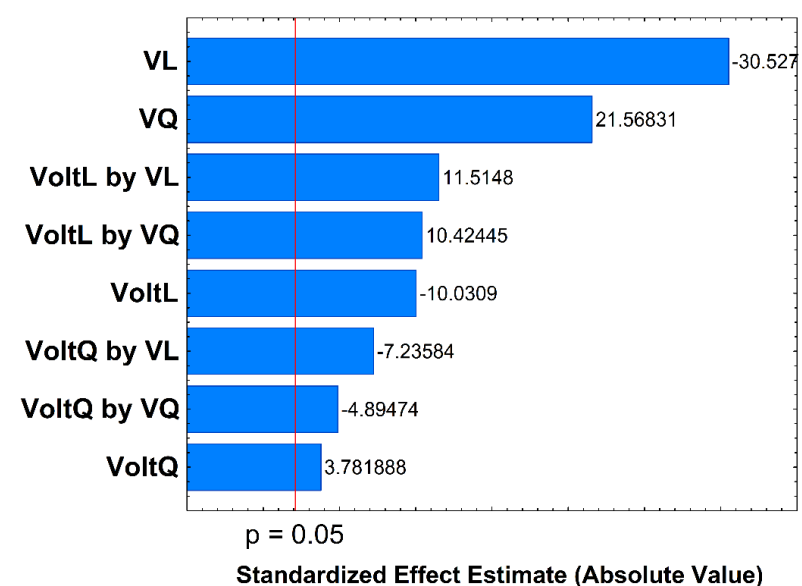

Figure 4 - Pareto chart for the overall mass efficiency of electrostatic precipitation
It is noted in Table 3 and Figure 4 that all linear and quadratic terms and their interactions are statistically significant for the response according to the analysis of variance, especially analyzing the p-values based on the F-test (Table 3) and considering a level of significance of 0.05 . The linear and quadratic terms of $V$ provided the strongest effects on the efficiency, which can also be noticed by Figure 3, for the range of values evaluated in this study.

Since ANOVA provided statistically significant relationships between the evaluated operating conditions and the collection efficiency, the RSM was applied for this case in order to fit a model that can be applied with scientific basis in further experiments regarding these three operating variables. Table 4 presents the results of the regression. The model was well fitted in the experimental data according to the statistical parameters obtained $\left(\mathrm{R}^{2}=0.99217\right.$; Adj. $=0.98869$; Residual Mean Square $=16.71913$ ) and the p-values exhibited in Table 4 that also shows the regression coefficients of the model and their $\pm 95 \%$ confidence limits. Therefore, the fitting model can be expressed as:

$$
\begin{aligned}
& E_{f f}=-258,670.4-63,448.4 \times \text { Volt }-3,889.2 \times \text { Volt }^{2}+49,674.6 \times V-1,803.9 \times V^{2}+ \\
& +12,177.6 \times \text { Volt } \times V-442.0 \times \text { Volt } \times V^{2}+746.4 \times \text { Volt }^{2} \times V-27.1 \times \text { Volt }^{2} \times V^{2}
\end{aligned}
$$


Table 4 - Regression coefficients for overall mass efficiency.

\begin{tabular}{|c|c|c|c|c|c|c|}
\hline Factor & $\begin{array}{l}\text { Regression } \\
\text { Coefficient }\end{array}$ & $\begin{array}{c}\text { Standard } \\
\text { Error }\end{array}$ & $\mathbf{t}(\mathbf{1 8})$ & P-value & $\begin{array}{c}-95 \% \\
\text { Confidence } \\
\text { Limit }\end{array}$ & $\begin{array}{c}+95 \% \\
\text { Confidence } \\
\text { Limit }\end{array}$ \\
\hline Mean./Interc. & $-25,8670.4$ & $29,232.7$ & -8.8 & $5.7 \times 10^{-8}$ & $-320,086.0$ & $-197,254.8$ \\
\hline Volt $(k V)$ - Linear (L) & $-63,448.4$ & $7,218.5$ & -8.8 & $6.3 \times 10^{-8}$ & $-78,614.0$ & $-48,282.8$ \\
\hline Volt (kV) - Quadratic (Q) & $-3,889.2$ & 445.6 & -8.7 & $6.9 \times 10^{-8}$ & $-4,825.4$ & $-2,953.1$ \\
\hline V (cm/s) - Linear (L) & $49,674.6$ & $8,322.2$ & 6.0 & $1.2 \times 10^{-5}$ & $32,190.2$ & $67,158.9$ \\
\hline V (cm/s) - Quadratic (Q) & $-1,803.9$ & 362.9 & -5.0 & $9.9 \times 10^{-5}$ & $-2,566.4$ & $-1,041.4$ \\
\hline VoltL by VL & $12,177.6$ & $2,055.0$ & 5.9 & $1.3 \times 10^{-5}$ & $7,860.2$ & $16,495.1$ \\
\hline VoltL by VQ & -442.0 & 89.6 & -4.9 & $1.1 \times 10^{-4}$ & -630.3 & -253.7 \\
\hline VoltQ by VL & 746.4 & 126.9 & 5.9 & $1.4 \times 10^{-5}$ & 479.8 & $1,012.9$ \\
\hline VoltQ by VQ & -27.1 & 5.5 & -4.9 & $1.2 \times 10^{-4}$ & -38.7 & -15.5 \\
\hline
\end{tabular}

The good fitting of the model to the experimental data can also be visualized by the plot of predicted values vs. observed values of Figure 5.

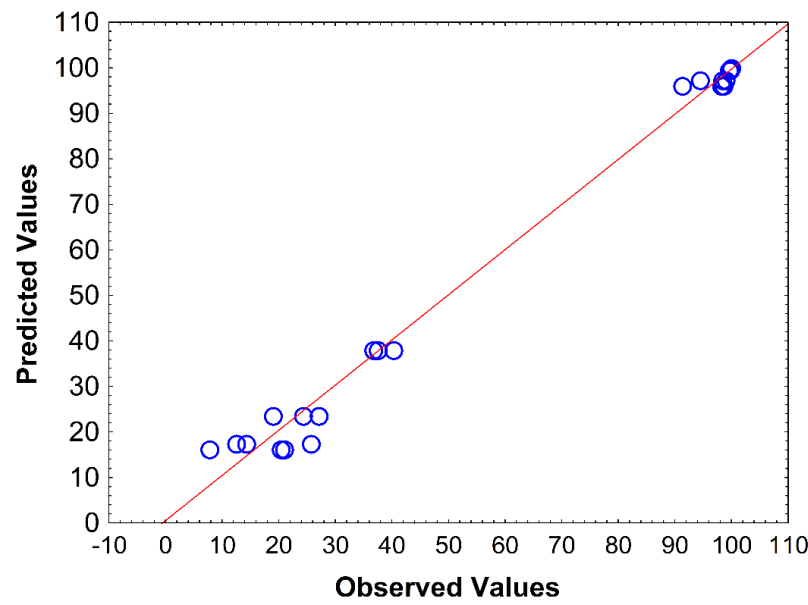

Figure 5 - Predicted values from the fitting model vs. observed values for overall mass efficiency

Figure 6 shows the fitted surfaces calculated using the model of Equation 3 at different angles (A, B) and the contour plot based on the fitted surface (C). It can be verified that there is a curvature of the response in relation to the air velocity, which was expected based on the experimental data. Although there is no critical point in the region evaluated since the dependence of the efficiency on the applied voltage is monotonic, it is possible to highlight some regions that provide the highest collection efficiencies, such as the ranges of $\sim 2-8$ $\mathrm{cm} \mathrm{s}^{-1}$ at $8.22-8.00 \mathrm{kV}$ (negative corona). The highest experimental efficiency $(99.870 \pm 0.008)$ was obtained for -8.2 $\mathrm{kV}$ at $6.67 \mathrm{~cm} \mathrm{~s}^{-1}$. It must be highlighted that although the fitted model provided values of efficiency higher than $100 \%$, obviously the real efficiencies cover values between zero and $100 \%$.

Table 5 presents the experimental and simulated values of overall mass efficiency for the operating conditions evaluated in this work, including the set of applied voltages at the air velocity of $3.3 \mathrm{~cm} \mathrm{~s}^{-1}$, with the respective errors. It is verified that the highest errors of the simulated results were in the order of $10^{-3}$ for the set of operating conditions evaluated. The highest error was $-26 \%$ for $-8.0 \mathrm{kV}$ at air velocity of $3.32 \mathrm{~cm} \mathrm{~s}^{-1}$. The other efficiencies obtained at this air velocity provided small errors, being 0.56 and $1.7 \%$ respectively for -8.1 and $-8.2 \mathrm{kV}$.

Table 5 - Experimental and simulated efficiencies and respective errors.

\begin{tabular}{|c|c|c|c|c|}
\hline Volt $/ \mathrm{kV}$ & $\mathrm{V} / \mathrm{cm} \mathrm{s}^{-1}$ & $\mathrm{E}_{\mathrm{ff}} / \%$ & $\mathrm{E}_{\text {model }} / \%$ & Error $\left(\left(\mathrm{E}_{\mathrm{ff}}-\mathrm{E}_{\text {model }}\right) / \mathrm{E}_{\mathrm{ff}}\right) / \%$ \\
\hline-8.0 & 1.67 & 38.08 & 38.08 & $4.5 \times 10^{-3}$ \\
\hline-8.1 & 1.67 & 96.03 & 96.03 & $6.2 \times 10^{-4}$ \\
\hline-8.2 & 1.67 & 99.61 & 99.61 & $-7.2 \times 10^{-4}$ \\
\hline-8.0 & 6.67 & 97.30 & 97.30 & $8.6 \times 10^{-5}$ \\
\hline-8.1 & 6.67 & 99.74 & 99.74 & $9.0 \times 10^{-4}$ \\
\hline-8.2 & 6.67 & 99.87 & 99.87 & $6.0 \times 10^{-4}$ \\
\hline-8.0 & 19.9 & 16.28 & 16.28 & $9.3 \times 10^{-3}$ \\
\hline-8.1 & 19.9 & 17.46 & 17.46 & $5.4 \times 10^{-3}$ \\
\hline-8.2 & 19.9 & 23.45 & 23.44 & $-8.1 \times 10^{-3}$ \\
\hline-8.0 & 3.32 & 85.71 & 63.07 & -26 \\
\hline-8.1 & 3.32 & 98.81 & 99.36 & 0.56 \\
\hline-8.2 & 3.32 & 99.81 & 101.5 & 1.7 \\
\hline
\end{tabular}


A)

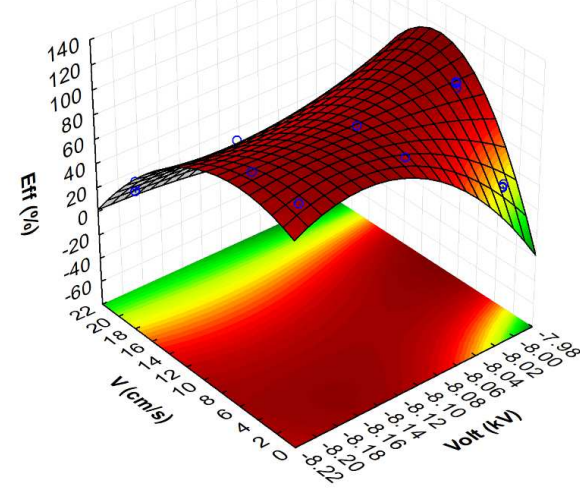

B)

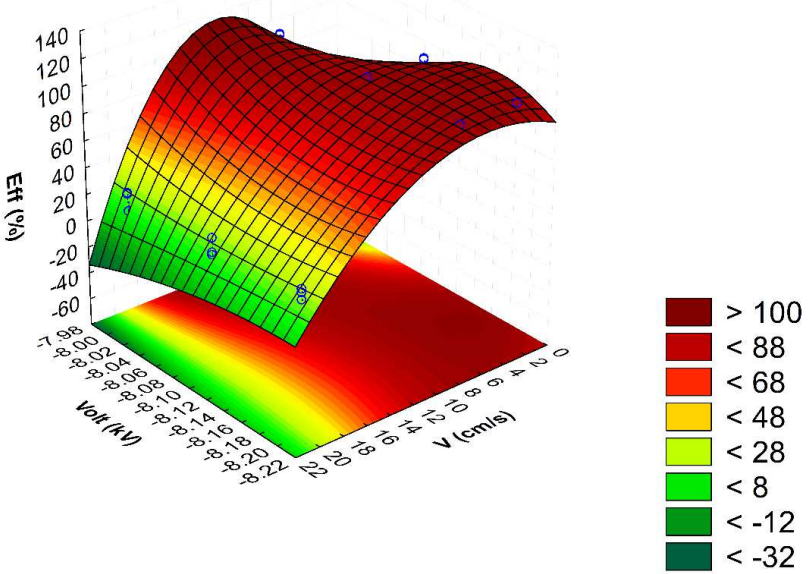

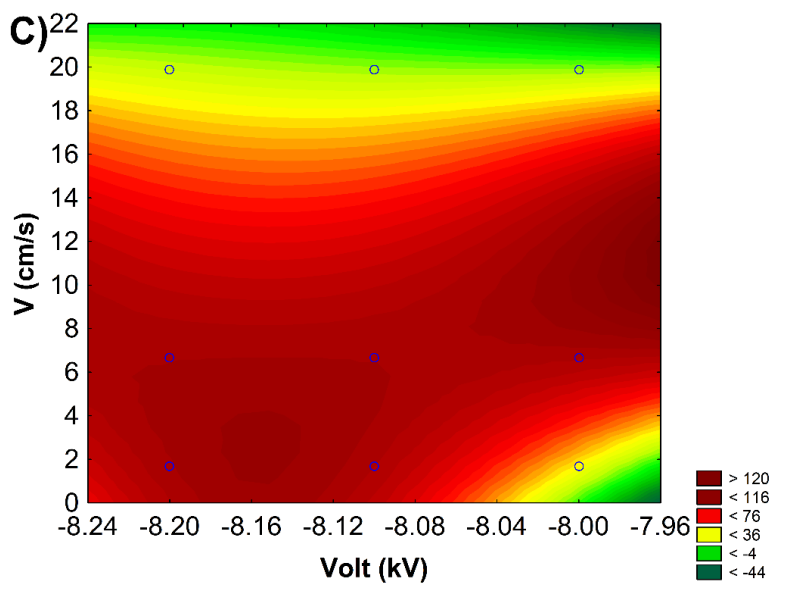

Figure 6 - Fitted surfaces (A, B) and contour plot for the overall mass efficiency (C)

In the scientific literature, RSM has been a useful tool to study the electrostatic precipitation and to predict the optimal operating conditions of this process, since it depends on several variables. Remaoun et al. (2012) evaluated the performance of a one stage, wire-plate ESP collecting welding fumes, varying the width of the collecting plate $(2,4,6,8$, and $10 \mathrm{~cm})$ and the electrode spacings $(2,3,5$, and $4 \mathrm{~cm})$ and obtaining a fitting model with $\mathrm{R}^{2}$ of 0.89 . The highest performance was obtained at the plate width of $10 \mathrm{~cm}$ with the electrode spacing of $3 \mathrm{~cm}$. Manuzon et al. (2014) used RSM to evaluate the effect of the applied voltage ( 9.4 to $13.6 \mathrm{kV})$ and the gas velocity ( 0.8 to 2.2 $\mathrm{m} \mathrm{s}^{-1}$ ) on a wire-plate ESP efficiency, obtaining a fitting model with $\mathrm{R}^{2}$ of 0.8125 and a maximum collection efficiency at 13.6 $\mathrm{kV}$ and $1.7 \mathrm{~m} \mathrm{~s}^{-1}$. The authors also evaluated the type and concentration of the $\mathrm{PM}_{1}, \mathrm{PM}_{2.5}$ and $\mathrm{PM}_{10}$ dust (poultry dust: 2, 4, and $9 \mathrm{mg} \mathrm{m}^{-3}$; flour: 1,3 , and $7 \mathrm{mg} \mathrm{m}^{-3}$; and Arizona dust: 7 and $14 \mathrm{mg} \mathrm{m}^{-3}$ ) and the time of the operation on the ESP performance, obtaining up to $89 \%$ of efficiency in laboratory scale. In turn, the present work covered the efficiency of nanoparticulate collection in the range of low gas velocities, which benefits the collection of nanoparticles by diffusion as discussed elsewhere (Hinds, 1998; Oliveira and Guerra, 2018, 2019 a, b). The achievement of optimal operating conditions with a statistically reliable method could facilitate the further design of high-performance indoor air cleaners to retain nanoparticles, for example, since they could be associated with human diseases as brain damage and Alzheimer's disease (Maher et al., 2016). Alternatively, optimal conditions could be used to retain ultrafine particles of valuable materials Nanda et al., 2011; Harra et al., 2012; Lähde et al., 2014), but at better cost-benefit ratios.

\section{CONCLUSION}

Analysis of variance showed that the effects evaluated were statistically significant for the overall mass efficiency of electrostatic precipitation of nanoparticles. The first increase of air velocity was responsible for the enhancement of the diffusional phenomena acting on the particles and the further increase provided the decrease of the residence time of the gas and particles in the electrostatic precipitator. The increase of the applied voltage resulted in the increase of the electric force responsible to influence the electrical charges that charged that particles and was also related to the electrical force that moved the particulate to the collection plates, in addition to be responsible for the increase of the turbulent mixing inside the device. Response surface methodology was useful to visualize regions that provide the highest efficiencies for the range of operating conditions evaluated in this work, since the fitting model was well adjusted to the experimental data $\left(\mathrm{R}^{2}\right.$ of 0.99217). 


\section{ACKNOWLEDGEMENTS}

The authors are grateful for the financial support provided by $\mathrm{CNPq}$ (131744/2017-8 and 141299/2019-3) and CAPES (001).

\section{REFERENCES}

BAI, H., LU, C., CHANG, C. L. A Model to Predict the System Performance of an Electrostatic Precipitator for Collecting Polydisperse Particles. Journal of the Air \& Waste Management Association, v. 45, n.11, p. 908916, 1995

CHEN, T.-M., TSAI, C.-J., YAN, S.-Y., LI, S.-N. An efficient wet electrostatic precipitator for removing nanoparticles, submicron and micron-sized particles. Separation and Purification Technology, v. 136, p. 27-35, 2014.

DEAN, J. A. Lange's Handbook of Chemistry. $15^{\text {th }}$ ed., U.S.A.: McGraw-Hill, 1999.

FUJISHIMA, H.; MORITA, Y.; OKUBO, M.; YAMAMOTO, T. Numerical Simulation of Three-Dimensional Electrohydrodynamics of Spiked-Electrode Electrostatic Precipitators. IEEE Transactions on Dielectrics and Electrical Insulation, v. 13, n. 1, p. 160-167, 2006.

GUO, B.-Y., YANG, D., SU, Y.-B., YU, A. B. Process modelling of low temperature electrostatic precipitators. Powder Technology, v. 314, p. 567-576, 2017.

HARRA, J.; MÄKITALO, J.; SIIKANEN, R.; VIRKKI, M.; GENTY, G.; KOBAYASHI, T.; KAURANEN, M.; MÄKELÄ, J. M. Size-controlled aerosol synthesis of silver nanoparticles for plasmonic materials. Journal of Nanoparticle Research, v. 14, p. 870-879, 2012.

HINDS, W. C. Aerosol Technology: Properties, Behavior, and Measurement of Airborne Particles, $2^{\text {nd }}$ ed., New York: John Wiley, 1998.

HUANG, S. H.; CHEN, C. C. Ultrafine aerosol penetration through electrostatic precipitators. Environmental Science and Technology, v. 36, p. 4625-4632, 2002.

KHERBOUCHE, F., BENMIMOUN, Y., TILMATINE, A., ZOUAGHI, A., ZOUZOU, N. Study of a new electrostatic precipitator with asymmetrical wire-tocylinder configuration for cement particles collection. Journal of Electrostatics, v. 83, p. 7-15, 2017.

KIM, H. J.; HAN, B.; KIM, Y. J.; YOA, S. J. Characteristics of an electrostatic precipitator for submicron particles using non-metallic electrodes and collection plates. Journal of Aerosol Science, v. 41, p. 987-997, 2010.

LÄHDE, A.; KOSHEVOY, I.; KARHUNEN, T.; TORVELA, T.; PAKKANEN, T. A.; JOKINIEMI, J. Aerosolassisted synthesis of gold nanoparticles. Journal of Nanoparticle Research, v. 16, p. 2716-2723, 2014.

LIN, G.-Y., CHEN, T.-M., TSAI, C.-J. A Modified DeutschAnderson Equation for Predicting the Nanoparticle Collection Efficiency of Electrostatic Precipitators. Aerosol and Air Quality Research, v. 12, p. 697-706, 2012.

LIN, G.-Y., TSAI, C.-J. Numerical Modeling of Nanoparticle
Collection Efficiency of Single-Stage Wire-in-Plate Electrostatic Precipitators. Aerosol Science and Technology, v. 44, p. 1122-1130, 2010.

MAHER, B. A., AHMED, I. A. M., KARLOUKOVSKI, V., MACLAREN, D. A., FOULDS, P. G., ALLOSOP, D., MANN, D. M. A., TORRES-JARDÓN, R., CALDERON-GARCIDUENAS, L. Magnetite pollution nanoparticles in the human brain. Proceedings of the National Academy of Sciences of the United States of America (PNAS), v. 113, n. 39, p. 10797-10801, 2016.

MANUZON, R.; ZHAO, L.; GECIK, C. An optimized electrostatic precipitator for air cleaning of particulate emissions from poultry facilities. ASHRAE Transactions, v. 120, p. 1-14, 2014.

MONTGOMERY, D. C.; RUNGER, G. C. Applied Statistics and Probability for Engineers, $6^{\text {th }}$ ed., Hoboken: Wiley, 2014.

MORAWSKA, L.; AGRANOVSKI, V.; RISTOVSKI, Z.; JAMRISKA, M. Effect of face velocity and the nature of aerosol on the collection of submicrometer particles by electrostatic precipitator. Indoor Air, v. 12, p. 129-137, 2002.

NANDA, K. K.; MAISELS, A.; KRUIS, F. E. Evolution of crystallinity of free gold agglomerates and shape transformation. RSC Advances, v. 1, p. 568-572, 2011.

NÓBREGA, S. W., FALAGUASTA, M. C. R., COURY, J. R. A Study of a Wire-Plate Electrostatic Precipitator Operating in the Removal of Polydispersed Particles. Brazilian Journal of Chemical Engineering, v. 21, n. 2, p. 275-284, 2004.

OLIVEIRA, A. E., GUERRA, V. G. Influence of particle concentration and residence time on the efficiency of nanoparticulate collection by electrostatic precipitation. Journal of Electrostatics, v. 96, p. 1-9, 2018.

OLIVEIRA, A. E., GUERRA, V. G. Effect of low gas velocity on the nanoparticle collection performance of an electrostatic precipitator. Separation Science and Technology, v. 54, n. 7, p. 1211-1220, 2019 a.

OLIVEIRA, A. E., GUERRA, V. G. Efficiency of electrostatic precipitation of $\mathrm{NiO}$ nanoparticles dispersed by atomization. Separation Science and Technology, v. 55, n. 13, p. 2400-2409, 2019 b.

PARKER, K. Electrical operation of electrostatic precipitators. U.K.: The Institution of Electrical Engineers, 2003.

PODLIŃSKI， J.; DEKOWSKI， J.; MIZERACZYK， J.; BROCILO, D.; CHANG, J. S. Electrohydrodynamic Gas Flow in a Positive Polarity Wire-Plate Electrostatic Precipitator and the Related Dust Particle Collection Efficiency. Journal of Electrostatics, v. 64, p. 259-262, 2006.

REMAOUN, S.-M.; TILMATINE, A.; HAMMADI, N.; MILOUA, F.; MEDLES, K. Optimisation of one stage electrostatic precipitator for welding fume filtration. Scientia Iranica, v. 19, n. 6, p. 1861-1864, 2012.

RIEHLE, C. Electrostatic precipitation. In: SEVILLE, J. P. K. (Ed.). Gas cleaning in demanding applications. U.K.: Blackie Academic \& Professional, 193-228, 1997. 
ROBINSON, M. C., HOLliS HALlETT, A. C. The static dielectric constant of $\mathrm{NaCl}, \mathrm{KCl}$, and $\mathrm{KBr}$ at temperatures between $4.2{ }^{\circ} \mathrm{K}$ and $300{ }^{\circ} \mathrm{K}$. Canadian Journal of Physics, v. 44, n. 10, p. 2211-2230, 1966.

STATSOFT INC., "STATISTICA Data Analysis Software System, Version 10," 2011.

ZHANG, J.-P., HU, D.-M., DAI, Y.-X., DING, Q.-F. An improved modeling for Collection Efficiency prediction of electrostatic precipitators under the applied magnetic field. International Journal of Applied Electromagnetics and Mechanics, v. 35, p. 263-279,
2011.

ZHIBIN, Z., GUOQUAN, Z. Investigations of the Collection Efficiency of an Electrostatic Precipitator with Turbulent Effects. Aerosol Science and Technology, v. 20, n. 2, p. 169-176, 1994.

ZHUANG, Y.; KIM, Y.J.; LEE, T.G.; BISWAS, P. Experimental and theoretical studies of ultra-fine particle behaviour in electrostatic precipitators. Journal of Electrostatics, v. 48, p. 245-260, 2000. 